Faculdade

de Ciências Econômicas UFRGS
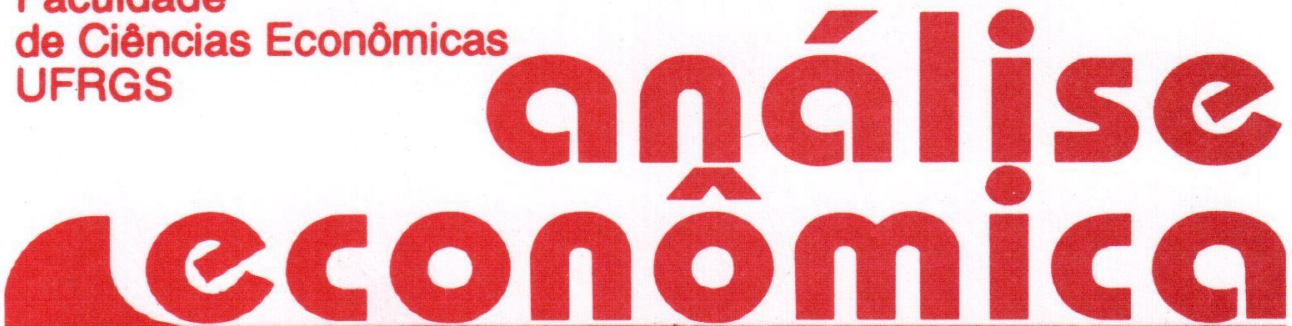

- A teoria NEOCLÁssica (PURA) E A TEORIA NEO-AUSTRIACA FRENTE AO LEGADO CARTESIANO Eleutério F. S. Prado

- MEdidAs de CONCENTRAÇÃo INDUSTRIAL: UMA RESENHA Marcelo Resende

- SISTEMA TRIBUTÁRIO E IMPOSTO ÚNICO SOBRE TRANSAÇÕES Ricardo Letizia Garcia

- ECONOMIA DO NORDESTE: TENDÊNCIAS DAS ÁREAS DINÂMICAS Policarpo Lima

- Custos e BENEFÍcIos DA INTEGRAÇÃO DO GRUPO ANDINO Marco Antônio Montoya

- Pós-graduAÇÃo EM ECONOMIa NOS ESTADOS UNIDOS DA AMÉRICA Egon Roque Fröhlich

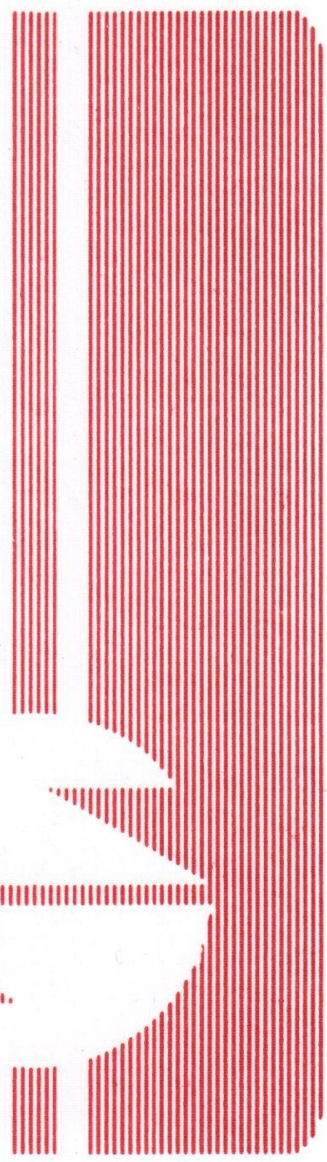


UNIVERSIDADE FEDERAL DO RIO GRANDE DO SUL

Reitor Prof Hélgio Henrique Casses Trindade

FACULDADE DE CIÊNCIAS ECONÓMICAS

Diretor Prof Pedro Cézar Dutra Fonseca

CENTRO DE ESTUDOS E PEQUISAS ECONÔMICAS

Diretor Prof. Paulo Alexandre Spohr

DEPARTAMENTO DE CIÉNCIAS ECONÓMICAS

Chefe: Prof Achyles Barcelos da Costa

CURSO DE PÓS-GRADUAÇÃO EM ECONOMIA

Coordenador Prof Nali de Jesus de Souza

CURSO DE PÓS-GRADUAÇÃO EM ECONOMIA RURAL

Coordenador. Prof Atos Freitas Grawunder

CONSELHO EDITORIAL: Achyles Barcelos da Costa, Aray Miguel Feldens, Atos Freitas Grawunder, Carlos Augusto Crusius, Fernando Ferrari Filho, Juvir Luiz Mattuella, Marcelo Savino Portugal, Maria Imilda da Costa e Silva, Nali de Jesus de Souza, Nuno R. L. de Figueiredo Pinto, Otília Beatriz K. Carrion, Paulo Alexandre Spohr, Pedro Cezar Dutra Fonseca, Roberto Camps Moraes, Valter José Stülp, David Garlow (Wharton Econometrics Forecasts Association, E.U.A.), Edgar Augusto Lanzer (UFSC), Eleutério Prado (USP), Fernando de Holanda Barbosa (FGV/RJ), Gustavo Franco (PUC/RJ), João Rogério Sanson (UFSC), Joaquim Pinto de Andrade (UnB), Juan H. Moldau (USP), Werner Baer (Univ. de Illinois, E.U.A.).

COMISSÃO EDITORIAL: Atos Freitas Grawunder, Pedro Cezar Dutra Fonseca, Marcelo Savino Portugal, Roberto Camps Moraes.

EDITOR: Nali de Jesus de Souza

SECRETARIA Cláudia Porto Silveira, Jeferson Luis Bittencourt e Vanete Ricachescki (revisão de textos)

FUNDADOR: Prof Antônio Carlos Santos Rosa

Os materiais publicados na revista Análise Econômica são da exclusiva responsabilidade dos autores. É permitida a reprodução total ou parcial dos trabalhos, desde que seia citada a fonte. Aceita-se permuta com revistas congêneres. Aceitam-se, também, livros para divulgação, elaboração de resenhas e recensōes. Toda correspondência, material para publicação (vide normas na terceira capa), assinaturas e permutas devem ser dirigidos ao seguinte destinatário:

PROF. NALI DE JESUS DE SOUZA

Revista Análise Econômica

Av. João Pessoa, 52

CEP 90040-000 PORTO ALEGRE - RS, BRASIL

E-MAIL: NALI@VORTEXUFRGS.BR

Telefones: (051) 316-3348 e 316-3440

Fax: (051) 225-1067 


\section{A TEORIA NEOCLÁSSICA (PURA) E A TEORIA NEO-AUSTRIACA FRENTE AO LEGADO CARTESIANO}

Eleutério F. S. Prado*

\section{SINOPSE}

Este artigo foi escrito na suposiçäo de que prestar atenção aos fundamentos filosóficos das teorias econômicas é importante, tanto para compreendê-las, quanto para ter consciência de suas fraquezas e limites. Sob esta orientação, faz-se um esforço para comparar a teoria neoclássica pura e a teoria neo-austriaca, investigando se aceitam ou rejeitam o legado cartesiano. Para caracterizar a teoria neoclássica pura empregam-se textos de Friedrich Hayek. Um resultado importante do artigo consiste em mostrar as diferenças entre os conceitos de equilíbrio adotados pelos dois autores.

\section{INTRODUÇÃO}

A teoria econômica contemporânea, sem dúvida, tem caminhádo - ainda que não necessariamente de modo progressivo - sem prestar atenção aos seus próprios fundamentos filosóficos. Pode-se dizer mesmo que não há boa vontade entre os economistas com as investigações reflexivas. Pois, examinar o modelo recém-publicado na literatura especializada é visto quase sempre como mais importante. Entretanto é difícil contestar a afirmação de que toda teoria econômica se baseia em uma metateoria filosófica e que esta lhe fornece uma visão do mundo em que se inclui um paradigma de homem e um padrão de sociabilidade.

No presente artigo é feito um esforço no sentido de relacionar as teorias neoclássica pura e neo-austriaca ao legado cartesiano. Não se faz referência aqui, entretanto, ao pensamento original de Descartes, mas ao modo como suas idéias subsistiram na ciência e se cristalizaram numa concepção depurada que se costuma denominar de cartesianismo. Para caracterizá-lo, segue-se a exposição de Bernstein em Beyond objetivism and relativism (Bernstein, 1988, p. 115-118). Para poder trabalhar com corpos teóricos mais consistentes, tomam-se como representantes da teoria neoclássica pura alguns trabalhos de Frank Hahn e como representantes da teoria neo-austríaca certos artigos o livros de Friedrich A. Hayek. Fazendo isso, além da vantagem óbvia mencionada, o presente artigo se beneficia também da autoridade dos escritos destes dois autores, assim como do fato de que eles já são, contrariamente ao grosso da literaiura, bem reflexivos.

"Professor do IPEIUSP.

\begin{tabular}{|c|l|c|}
\hline $\begin{array}{c}\text { Cód. AEA } \\
030\end{array}$ & $\begin{array}{l}\text { Palavras-chave: racionalidade, teoria econômica pura, } \\
\text { processo de mercado. }\end{array}$ & \\
\hline
\end{tabular}

\begin{tabular}{|l|l|l|r|}
\hline ANÁLISE ECONÓMICA & ANO 12 & março e setembro/94 & p. 5-23
\end{tabular}


A tese que o artigo apresenta pode ser facilmente resumida: enquanto a teoria neoclássica pura é cartesiana, a teoria neo-austríaca é anticartesiana. Quer-se mostrar, dizendo de outro modo, que elas se opõem completamente quanto à aceitação das teses que compõem o legado cartesiano. Para tanto, em seqüência, faz-se primeiro um esforço para tornar evidente a presença destas teses na teoria neoclássica pura e, depois, para mostrar como estas mesmas teses são rejeitadas pela teoria neo-austríaca. É claro que se o esforço for bem-sucedido, ele contribuirá para melhorar a compreensão da teoria económica. Que não se pense, porém, que as considerações que se seguem são neutras para o modo de fazer política econômica.

\section{DA TEORIA NEOCLÁSSICA}

Por duas vezes pelo menos Frank Hahn definiu a teoria neoclássica relacionando três caracteristicas. Em uma delas, escreveu que esta teoria sempre envolve os seguintes elementos: a) reducionismo, ou seja, o principio metodológico que "busca centrar as explanações nas ações dos agentes individuais"; b) comportamento racional - pois, nesta teoria, atribui-se sempre aos agentes um comfortamento que segue "certos axiomas de racionalidade" ; c) equilibrio, ou seja, a visão de que "alguma noção de equilibrio é necessária e que o estudo dos estados de equilíbrio é útil" (apud Addleson, 1986, p. 4).

Em outra, ele mencionou que a perspectiva neoclássica requer que os seguintes três pontos sejam observados" i) primeiro, "a economia fica completamente descrita pelas preferências e dotações dos agentes e pelos conjuntos de produção das firmas", ii) segundo, nesta economia, "todos os agentes tratam os preços parametricamente"; iii) terceiro, "todos os agentes são racionais", isto é, "dados os preços, eles tomarão aquele curso de ação que é o melhor para eles segundo as suas preferências, dentre os que thes estão disponiveis" (Hahn, 1982, p. 354)

Antes de prosseguir, é bom observar que esses dois conjuntos de características, mesmo sendo consistentes entre si, não são equivalentes. Em particular, o primeiro deles afigura-se excessivamente abrangente e impreciso. Com alguma tolerância interpretativa, entretanto, é possivel mesmo dizer que eles se complementam. Note-se que se "i" implica logicamente "a", o inverso não é verdadeiro, já que o reducionismo pode envolver uma especificação de indivíduo constituinie da economia distinta da contida em "i"; na verdade, " $i$ " particulariza e especifica o conteúdo de "a". Note-se que "c" não tem contrapartida no seguñdo conjunto de características. Note-se, também, que "ii" é independente do primeiro deles. Observe-se, finalmente, que se "b" e "iii" tratam da mesma questão, "b" é geral o suficiente para englobar concepçōes distintas da noção neoclássica de racionalidade; veja-se, entretanto, que "iii" especifica com certa precisão este conceito. ${ }^{1}$

Mesmo levando em consideração os dois conjuntos de determinações acima apresentados, é possivel mostrar que Frank Hahn, desse modo, caracteriza insuficientemente a teoria neoclássica pura. E que, para fazê-lo de modo melhor, é

\footnotetext{
1 Uma especificação mais detalhada do conceito neoclássico de racionalidade encontra-se em $A$ Constelação pós-walrasiana (Prado, 1994).
} 
preciso investigar as raizes cartesianas do programa de pesquisa iniciado por Walras. Entre outros, Koppl e Mirowski argumentaram convincentemente que para entender Walras - assim como toda a economia walrasiana - é preciso compreender como ai se conserva o legado filosófico de Descartes (Koppl, 1982; Mirowski, 1987). Ademais, muitos filósofos, entre eles Bernstein, tem chamado a atenção, enfaticamente, para a influência do cartesianismo na ciência moderna (Bernstein, 1988; Burtt, 1991).

Antes de mais nada, é preciso lembrar que a tradição cartesiana é dualista, pois se caracteriza antes de tudo por distinguir e separar o mundo do pensamento (res cogitans) do mundo material (res extensa), estabelecendo entre eles uma relação de dominação que se reflete na dicotomia sujeito e objeto. Como se sabe, o primeiro deles caracteriza estritamente o homem como tal. Este é concebido como um ser individual dotado de entendimento e vontade, ou seja, da faculdade de alcançar a verdade e da capacidade para agir segundo o próprio livre-arbítrio. É como espírito racional e autônomo (dono de si mesmo), portanto, que o homem aparece na tradição cartesiana. Já a natureza é vista como uma esfera sem qualquer dinamismo ${ }^{2}$ próprio, ou seja, como puro mecanismo ${ }^{3}$ Tudo nela acontece segundo leis de causalidade eficiente, ou seja, de repetição do idêntico, de tal modo que pode ser apreendido suficientemente pela razão analitica e dedutiva. Despida de qualquer sentido e finalidade, a natureza afijura-se, então, como uma esfera de regularidades, inteiramente transparente à linguagem matemática e que está à disposição do homem para a sua exploração. ${ }^{4}$

Essa dicotomia aparece na teoria neoclássica porque ela concebe a economia como composta, de um lado, por agentes - caracterizados por suas preferèncias e, de outro, por coisas entendidas como bens - meras congéries de qualidades que são selecionadas ou imprimidas às matérias-primas numa atividade produtiva que pode ser descrita por conjuntos ou funções de produção. Nessa perspectiva, a produçāo não é um processo criativo - não é, na verdade, nem processo nem criação nos verdadeiros sentidos destas duas palavras - mas apenas transformação laplaciana da matéria (e da energia). O próprio trabalho entra aí, como bem se sabe, como mero fator de produção mecânico -- como atividade de um corpo capaz de se mover e de mover outros corpes.

Por outro lado, os agentes da economia neoclássica são racioriais, isto é, "saivem o que querem e, dentre as alternativas disponiveis, escolhem o que desejam" (Hahn, 1984, p. 5). Ora, se os agentes sabem o que querem, mostram que são dotados de entendimento; se eles escolhem o que desejam é sinal de que são

\footnotetext{
${ }^{2}$ O termo "dinamismo" aqui empregado remete-se à metafisica que apresenta os fenômenos da natureza como ocorrências produzidas pc: forças e potências abstratas inerentes às coisas observadas.

3 Talvez seja muito forte falar aqui em "puro mecanismo", pois a concepção de natureza da ciência moderna modificiou-se substancialmente do século de Descartes (século XVII) para o século de Einstein (século $X X$ ). Entretanto, mesmo havendo mudado, é-lhe inerente representar sempre o mundo natural como uma grande máquina - mecânica, energética, orgânica, cibernética --, em que estão ausentes quaisquer determinações teleológicas ou espirituais.

4 "Como a coisa não se conhece e não se possui" - diz Walras, significativamente _.. "... pode ser assimilada a um puro mecanismo". Como as pessoas agasalham finalidades e procuram realizar o seu destino, têm, justamente por isso, "... toda a faculdade, toda a liberdade de subordinar a finalidade das coisas à sua própria finalidade" (Walras, 1983, p 16)
} 
dotados de vontade. Mas, o que significa isso, mais precisamente? No mesmo texto de Hahn encontra-se uma resposta bem explícita para essa questão: "se os agentes têm preferências é o mesmo que pretender que eles são pessoas" (idem, p. 6). Pois, se alguém tem preferências - argumenta -, é capaz de entender o que significa dizer, por exemplo, que a opção "a" é melhor do que a opção "b "e, assim, é capaz de apresentar razões para as suas ações. Em caso contrário, se algo não tem preferências - convém -- este algo apenas pode ser descrito por suas "características físicas". Se, porém, ainda assim este algo "escolhe", ou seja, parece revelar que tem preferências, é porque "deve ser um animal e não uma pessoa" (idem, p. 5-6). Vale lembrar, aqui, que os animais - inclusive o homem enquanto corpo - são puros mecanismos para Descartes e Walras (Descartes, 1983b, p. 93; Walras, 1983 , p. 16). Hahn, entretanto, como um cientista do século $X X$, tem obviamente uma compreensão mais complexa do que apenas é descritivel por suas "caracteristicas físicas"

A segunda caraterística importante do cartesianismo é a crença inabalável no esforço de purificação do intelecto por si mesmo, com o fim de chegar ao conhecimento claro e distinto. Para ele, trata-se de um caminho interior, por meio do qual o sujeito, solitária e monologicamente, aclara o seu intelecto, mediante a dúvida metódica Pois, para que este esforço seja bem-sucedido, o sujeito precisa colocar sob suspeição as suas opiniões e os seus preconceitos, deve pôr entre ३arênteses tudo o que não pareça evidente como tal. Se assim procede, resolutamente, o sujeito acaba encontrando - acredita o cartesianismo - pontos arquimedianos para a construção de um conhecimento demonstrativo que pretende que seja não menos do que muito bem fundamentado.

Ora, é sabido que a teoria pura de inspiração walrasiana busca fundações seguras, ou seja, consiste numa estrutura lógica derivada de axiomas evidentes por si mesmos; como diz Hahn, "as suas proposições são deduziveis de traços bem aceitos do mundo" (Hahn, 1984, p 5) E, pois, na própria teoria, ou seja, nas caracteristicas dos agentes econômicos, que a autotransparência acima mencionada se mostra inteiramente. Nesta teoria, não se considera, é certo, o esforço de auto-aclaramento desses agentes; eles entram em cena no mercado prontos para a tomada de decisão o que é importante notar é que eles são pensados ai como seres que têm um conhecimento rlaro e distinto, completo e inequívoco, das próprias preferências assim como das técnicas de produção disponiveis Só concebidos desse modo podem se tornar axiomas; só assim pode ser encontrado um fundamento seguro para o exercicio dedutivo. A supressão do auto-aclaramento na teoria, aliás, é uma limitação que os teóricos do equilibrio geral não se esquecem de apontar. Hahn menciona, por exemplo, que "o tempo e o esforço gasto na descoberta das esco'has possiveis" e "o auto-exame erivolvido na busca de preferências completas c consistentes" faz parte "deste dominio", ou seja, do campo das escolhas possiveis (Hahn, 1984, p. 8).

A terceira característica do cartesianismo é a perfeição do sujeito. Este é concebido como alguém dotado de ampla liberdade de escolha e de plena capacidade de chegar à verdade por meio do próprio entendimento. Dito de outro modo, o sujeito é posto como um ser capaz de julgar e de fazê-lo de modo correto. Em principio, pois, não há defeitos inerentes ao seu intelecto e à sua vontade. Entretanto isto não significa dizer que o homem não possa nunca ignorar, cometer 
erros cognitivos ou desejar o que não pode ser obtido. Implica pensar, isto sim, que esta possibilidade só vem a ocorrer porque ele, sendo finito, pode fazer mal uso de sua capacidade cognitiva e de seu poder de decisão.

A característica da perfeição se manifesta tanto na compreensão da teoria neoclássica pura quanto como propriedade do conhecimento e da vontade dos agentes econômicos. Para ver isto, entretanto, é preciso ter em mente que estes agentes não são tipos reais, mas "tipos ideais", pois "a idealização $e$ o robustecimento dos traços bem aceitos do mundo" - com diz Hahn - "é uma das marcas distintivas da teorização" (Hahn, 1984, p. 7). Aliás, uma idéia semelhante encontra-se em Walras. Diz este último autor que as ciências puras, inspiradas na matemática, "abstraem desses tipos reais, tipos ideais, que definem; e com base nessas definições, constroem a priori todos os andaimes de seus teoremas e demonstrações" (Walras, 1983, p. 24)

Para Hahn, a teoria pura pode se mostrar inadequada frente à realidade, mas somente por causa de "nossa" limitaçăo cognitiva: "na verdade" - diz ele, por exemplo -, "uma das razões porque uma noção de equilibrio é útil é que ela serve para tornar preciso os limites da análise econômica". Em outras palavras, o principal resultado da teoria pura é uma conquista definitiva da razão analitica e dedutiva que, apesar de suas limitações, diz o que pode e o que não pode ser dito em Economia. Eis que os economistas aprenderam algo sobre a situação de equilibrio, mas ainda não conseguiram avançar quase nada sobre o que aco \$tece fora dele "Em nosso estágio atual de conhecimento... é a rotina comportamental e não o comportamento como tal que podemos ter esperança de descrever"

No modo de teorização aqui discutido, os agentes, em primeiro lugar, precisam ser pensados como racionais. Mas isto não é tudo $\mathrm{Na}$ medida em que eles são racionais, em segundo luyar, ela se obriga a pensá-los como perfeitamente racionais. Isto é, ela precisa supor que os agentes sabem tudo o que precisam

${ }^{5}$ E preciso não confundir este conceito "tipo ideal" com o de Weber Enquanto que o primeiro é substantivo, este último é sempre uma construção formal do cientista para analisar configurações históricas precisas. Enquanto que o primeiro visa uma universalidade subjacente à complexidade fenomênica, o de Weber visa as particularidades desta complexidade que 0 cientista quer ressaltar.

"A expressão "traços hem aceitos do murido" (agreed features of the world) empregada por Hahn tem de ser lida sabendo que ele nega que "verdade é questão de sociologia", ou seja, algo que aflora na interação dialógica, mas afirma que a "teoria deve ser de domínio público", ou seja, algo "que pode ser objeto de comunicação por meio da linguagem e da gramática corrente" (Hahn, 1993, p 4-5). Onde ele se apóia, afinal, para afirmar a verdade dos axiomas e a validade da teoria? Mesmo se não apela em última instância para Deus, tal como Descartes, na busca de fundamentos primeiros, Hahn não pode deixar de recorrer à intuição racional: "os axiomas... constituem se em afirmações tão amplamente aceitas que tornam desnecessária a busca de argumentos adicionais" (idem, p. 5). Ora, sem cair em circularidade, ele só pode considerar os axiomas como "amplamente aceitos" porque os considera como evidentes por si mesmos, indubitáveis e certos para todos os sujeitos cognoscitivos racionais. "eles apelam à rossa intuição e ao que sabemos sobre nós mesmos" (idem, p. 5). Walras, afirmando a realidade do universal, menciona explicitamente o caráter platônico da teoria econômica pura: "a ciência" diz ele - "dedica-se à busca da verdade pura". Esclarecendo, pouco depois, de que verdade se trata: "há muito tempo ficou esclarecido pela filosofia platônica que a ciéncia não estuda os corpos, mas sim os fatos dos quais os corpos são o teatro. Os corpos passam; os fatos permanecem" (Walras, 1983, p. 8, 15). 
saber para tomar decisões bem determinadas. Assim, tem de admitir que eles conhecem as suas preferências, as suas dotaçōes, todos os bens trocados no mercado e os seus preços, ainda que não tudo (eles não conhecem, por exemplo, as preferências dos outros agentes). Ademais, a racionalidade neoclássica é objetivista, pois ela supōe que o conhecimento do agente é correto, ou seja, imagina que ele corresponde exatamente aos fatos. Dito de outro modo, os agentes aí descritos por axiomas não estão limitados por qualquer ignorância relevante e não cometem erros cognitivos. $E$ fácil ver que se assim não fosse - ou seja, supondo que o seu conhecimento fosse falho - o conteúdo deduzido ficaria comprometido. O equilibrio geral seria, assim, um desequilibrio e a "mão invisivel" não teria conseguido completar a sua tarefa?

Uma quarta característica dessa tradição vem a ser correlacionar a verdade ao julgamento - é dita racionalista, por isso - e não à experiência, como faz o empirismo.

Veja-se, por exemplo, como Frank Hahn critica a afirmação falaciosa de que não é necessário se preocupar com os recursos exauriveis porque os preços de mercado asseguram o seu uso apropriado. Ele não apela ao conhecimento empírico para mostrar, diretamente, que esta afirmação é falsa, por exemplo, dizendo que tal opiniäo exprime uma crença no mercado que ignora as suas falhas alocativas correntemente constatáveis por qualquer observador. De modo diferente, ele sugere o seguinte procedimento supostamente rigoroso: mostrar, primeiro, que a afirmaçầ' vale em uma economia de Arrow-Debreu, lembrando, depois, que na economia real não estão presentes todos os mercados futuros contingentes, tal como acontece na abstração teórica. Para ele, este procedimento se justifica, pois "os homens práticos e os teóricos mal treinados em todos os lugares do mundo" - entre eles estaria, certamente, Adam Smith! - "não entendem o que pretendem estar dizendo quando atribuem um papel coerente e benéfico à mão invisivel".

A quinta característica do cartesianismo vem a ser uma confiança inabalável no método axiomático dedutivo. Depois de encontrados fundamentos claros e seguros, é sempre possivel construir - acredita - um grande e sólido edifício de conhecimentos. Ao observar estritamente as regras desse método, o sujeito cognoscitivo pode estender sistematicamente, de modo seguro, o conhecimento, ou seja, sem erros.

Esta característica também sparece na teoria neocláscica, no nivel metodológico; é encontrada, por exemplo, no escrito de Frank Hahn em louvor da teoria econômica, de 1984. O que ele ai entende por teoria econômica? Por isto ele compreende simplesmente a teoria pura, ou seja, "a atividade de deduzir implicações a partir de um pequeno número de axiomas" (Hahn, 1991, p. 47). Niesse artigo, Hahn não apenas professa uma confiança inabalível nesta forma de teorizar, mas sugere com certa arrogância que esta é a única forma digna de crédito. "Para alguns economistas" - diz Hahn - "a teoria axiomática, lógica e dedutiva, é um anátema; por exemplo, este é o caso do Professor Kornai e do Lorde Kaldor". Porém, para ele próprio que se confessa surpreendido com estas opiniões

7 Frank Hahn menciona que a prova da existência na teoria do equilibrio geral consiste "no primeiro passo numa discussáo séria sobre a mão invisivel que 'cumpriu a sua tarefa' " (Hahn, 1984, p. 13). 
absurdas, "uma teoria" - se é que ela é, efetivamente, teoria - "terá tipicamente uma estrutura lógica derivada de axiomas" (Hahn, 1984, p. 5). Apenas sob a luz de certos princípios abstratos unificadores - crê ele - pode-se entender certos aspectos particulares da realidade econômica.

Um outro elemento distintivo do legado de Descartes é a crença exclusiva no tribunal da razão. Tal crença afirma simplesmente que não há outra autoridade no julgamento de uma pretensão de conhecimento do que a própria razão. Esta é compreendida, pois, como uma soberana que pode governar de modo universal a formação do conhecimento, independentemente de todo contexto histórico. Em conseqüência, a validação do que pretende ser saber não pode depender, para o cartesianismo, do testemunho dos sentidos, da opinião prevalecente, dos preconceitos e da tradição. A sétima e última característica desta tradição concerne ao papel exclusivamente epistemológico da experiência, a qual é entendida com uma relação meramente cognitiva entre o sujeito e o objeto.

Antes de mencionar como se manifesta na teoria neoclássica esses dois últimos pontos, vale lembrar que se encontra na filosofia cartesiana - como aponta Bernstein - a origem do "contraste iluminista entre razão e tradição, razão e autoridade, razão e superstição" (Bernstein, 1988, p. 117). E que este contraste, enxergado como disjunção e antagonismo, faz nascer profunda suspeita e hostilidade em relação aos estudos históricos e hermenêuticos. Não é à toa, portanto, a ênfase que Hahn põe na capacidade da teoria pura em livrar os homens do irracional Visando o entendimento analítico e dedutivo do mundo - esclarece - "a teoria é poderosa em nos poupar de idéias extravazantes e de bruxas" (Hahn, 1984, p. 12)

Nada revela melhor a hostilidade dos teóricos puros ao contextual e ao históricn do que a apreciação desconsolada de Hahn sobre certos desdobramentos recentes do programa de pesquisa neoclássico. "A teorização do tipo puro" - prevê ele, neste fim de século, pensando nas próximas décadas -, "vai se tornar muito menos possivel e, assim, menos passivel de apreciação". E por razões internas ao próprio desenvolvimento das pesquisas A crítica de Simon, por exemplo, colocou na agenda a noção de "racionalidade limitada", o que está fazendo o desenvolvimento da ciência "escapar do 'maquinismo' para cair no carmpo das 'regras práticas" (Hahn, 1991a, p. 47-48). A teoria dos jogos já convive com certa arbitrariedade, pois os seus teóricos não conseguem chegar a um acordo sobre a noção de solução; fala-se ai, inclusive, em soluções salientes, "o que não é exatamente um conceito preciso". Em certos modelos de mercados incompletos, mostrou-se rue um amplo conjunto de equilibrios é possivel, mas não que um deles é mais provável.

Em suma, as pesquisas em economia pura caminham, mas no caminho as indeterminações se multiplicam. Diante delas - nota Hahn - ressurgem os elementos contextuais e históricos no próprio seio da teoria pura. Em consequencia, para dar continuidade às investigações, "ao invés de teoremas, serão necessánas simulações, ao invés de axiomas simples e transparentes aparecerão provavelmente postulados históricos, sociológicos e psicológicos" (Hahn, 1991a, p 40). Em muitos casos, a determinação do equilibrio dependerá do processo histórico imaginado que o engendra, para Hahn, isto não é bom: "as implicações... não são agradáveis... [pois, assim,] o computador tomará crescentemente o lugar dos teoremas" (Hahn, 1991b, p. 73). 
Por se aferrar ao dualismo cartesiano, a teoria de inspiração walrasiana também enfrenta o problema da conciliação - impossivel nos seus termos - entre a "res cogitans" e a "res extensa", entre o que é livre e clarividente (o agente) e o que é maquinal e monótono (a economia). Walras, depois de classificar os fatos do mundo em fatos naturais, os quais "têm sua origem no jogo das forças da natureza, que são forças cegas e fatais", e em fatos humanitários, que "têm sua origem no exercício da vontade do homem, que é uma força livre e clarividente", vai concluir, de um modo revelador, que se "o valor do trigo em dinheiro... não resulta nem da vontade do vendedor, nem da vontade do comprador, nem de um acordo entre eles", então, ele vem a ser um "fato que tem o caráter de um fato natural" (Walras, 1983, p. 16, 23). Assim, o valor e o preço, que têm uma existência meramente simbólica, aparece de um modo obscuro como algo material, existente independentemente da vontade humana. Mas este não é, precisamente, o fulcro do problema. Assim, o homem, pensado sobretudo como um ser teleológico capaz de üar finalidade às suas ações e ao que as suas ações produzem, surge de um modo intransparente como um ser sujeitado a um funcionamento maquinal, determinante de seu comportamento.

Hahn, em um de seus textos mais importantes, contesta a crítica corrente que acusa a teoria neoclássica de erro por centrar no agente individual - e não nas instituị̧ões do capitalismo - a explanação do mercado. Ao contrário do que se pensa, diz ele, "a teoria tradicional do equilibrio apresenta-se melhor quando o individuo não tem importância - quando a sua medida é zero... [e] as instituições sociais da propriedade e do mercado têm o papel predominante". Eis que, assim, as pessoas antes referidas como tais se revelam, agora, como meras peças de uma máquina. Eis que, assim, ademais, depois de fazer aparecerem as instituições desaparecidas, Hahn faz o reducionismo se mostrar como um sistemismo mecânico. Depois de lembrar que a ambição dessa teoria é mostrar como de ações individuais independentes resulta, não intencionalmente, um estado social coerente, arrisca-se numa manobra retórica reveladora das suas próprias dificuldades: "segundo penso, os teóricos do equilibrio geral estão mais próximos de Marx do que muitos marxistas!" (Hahn, 1973, p. 33) ${ }^{9}$

A economia real, na perspectiva da ontologia cartesiana, à medida que é uma esfera de exterioridade, somente pode ser concebida como uma grande máquina cujas características são exprimiveis inteiramente por meio da matemá́tica. $\mathrm{Em}$ conseqüência, na sua compreensão teórica, não se pode empregar categorias que expressani teleologias objetivas Frank Hahn rejeita a idéia corrente de que o equilíbrio é o ponto para o qual converge o processo econômico. A teoria do equilíbrio geral, convém ele, não supõe que uma seqüência de estados da economia termina necessariamente em um estado de equilibrio. Apenas diz que

\footnotetext{
- A característica "i" acima mencionada - note-se - oculta as instituiçôes ao dizer que "a economia fica completamente descrita pelas preferéncias e dotações dos agentes... ". Ela não faz qualquer menção ao papel das instituições na constituição do sistema econômico e dos próprios agentes econômicos.

9 Ora, onde Marx vê contradiçōes, os teóricos do equilíbrio geral enxergam coerência! Marx, ao contrário do que pensa Hahn, não anula o sujeito social, mas apenas considera que este não existe como tal, plenamente, no capitalismo. Para este crítico, isto sim, o homem existe aí na condição de homem alienado, ou seja, como ser ativo e prático que constrói a sociedade e faz a história sem consciência, cegamente.
} 
"nenhuma seqüencia plausivel de estados termina, se terminar de algum modo, num estado que náo seja o de equilíbrio" (Hahn, 1973, p. 7).

O cartesianismo reflete-se também na noção neoclássica de equilibrio de outro modo. Para percebê-lo é preciso prestar atenção à maneira como é definido. Vejase que Hahn, na citação anterior, associa de algum modo o conceito de equilibrio à idéia de estado terminal e de ausência de movimento. Eis que isto implica que, estando no equilíbrio, os agentes perdem toda motivação para mudar suas opções escolhidas. Por outro lado, Hahn conceitua o equilibrio como um estado da economia em que "as ações intencionadas dos agentes econômicos racionais são mutuamente consistentes, podendo por isso serem implementadas" (idem, p. 2). Eis que isto, por sua vez, implica que os agentes só mantêm sua motivação para mudar de opção fora do equilibrio: "os agentes não manterão as suas opções em estados nos quais estão disponíveis opções mais preferidas ou mais lucrativas" (idem, p. 7). Reunindo essas duas conclusões, chega-se, assim, a uma conclusão maior, da máxima importância: dadas as preferências, os agentes neoclássicos só modificam as suas decisões movidos por causação externa e nunca por iniciativa própria, ou seja, por motivação que se origina de um dinamismo próprio do homem. $E$ o que pode resultar da adesão à ontologia cartesiana que leva a pensar a economia como uma máquina.

Esta conclusão torna necessário lembrar aquui de um artigo de Joan Robinson. Em History versus equilibrium (1978), ela chamou a atenção para o fato de que a noção neoclássica de equilibrio está em total oposição ao de história: "tão logo" escreveu ela - "admite-se incerteza nas expectativas que guiam o comportamento econômico, o equilibrio cai fora do argumento e a história toma o seu lugar". Para ela, pois, tal noção de equilibrio suprime o processo histórico da análise econômica, abolindo, em particular, o processo de acumulação de capital. Não deixa de mencionar, em seqüência, a razão pela qual tal oposição ocorre necessariamente Segundo ela, a concepção neoclássica de equilibrio, baseada numa analogia mecânica, é incompativel com a idéia de uma economia habitada por seres humanos pois envolve a noção de previsão perfeita: "a vida humana não existe fora da história e ninguém aí tem a previsão perfeita de seu próprio comportamento futuro" (Robinson, 1978, p. 126-127). Este vem a ser um modo interessante de colocar as coisas, já que pensar a racionalidade como supressão da incerteza, ao mesino tempo em que se concebe o mundo-objeto cono transparente à matemática, é uma das características centrais do cartesianismo. Entretanto aqui se supj̃e que a economista inglesa, apesar de levantar e desenvolver uma questão importante, não chega a tornar explicito o ponto que a resolve.

Contra o comentário crítico de Joan Robinson, encontra-se em Hahn a observação trivial de que "uma norãa de equilibrio sempre se encontra em Economia" (Hahn, 1973, p. 2). Se assim é, ele passa imediata e desafiadoramente a lembrar de Marx. ${ }^{10}$ Este autor, ao se interessar pelas leis da história, não trabalhou também na teoria do valor e do preço com uma concepção de equilibrio? Se assim

${ }^{10}$ Diz Hahn: "a análise marxiana do valor e dos preços, até o ponto em que é compreensivel para mim, parece-me estar descrevendo uma economia em equilibrio" (Hahn, 1973, p. 1). Mesmo se isto fosse correto, Hahn poderia ter se perguntado se a noção de equilíbrio em O capital coincide com a noção neoclássica de equilibrio. É evidente, entretanto, que ele está errado. 
é, como criticar a noção neoclássica de equilibrio justamente da perspectiva da história? Ocorre que está última não pode ser identificada com a noção de equilibrio em geral. Por que? Simplesmente porque, como se viu acima, ela tem como particularidade negar que o agente económico, enquanto tal, seja um homemsujeito. E a noção moderna de história, enquanto processo de desenvolvimento, envolve necessariamente a idéia de sujeito histórico, ou seja, de um homem ativo que faz a história, mesmo que seja cegamente. "Sendo enfático, ela é totalmente incompativel com a idéia, para empregar uma expressão do próprio Hahn, de um homem cuja medida é zero. É é justamente a este marco, como se viu, que chega a compreensão cartesiana da economia.

Nesse sentido, uma noção de equilibrio compativel com a de processo histórico só precisa sustentar que, mesmo se a economia vier a se encontrar eventualmente neste estado, a motivação dos agentes econômicos, por exemplo, para obter mais lucro, não cessa. Ela faz a economia crescer, crescer, crescer, indefinidamente, porque a motivação dos agentes mora na acumulação de capital, e não simplesmente num estado de ótimo. É o que se encontra - admite-se aqui - em Marx.

\section{DA TEORIA NEO-AUTRIACA}

- Se a teoria neoclássica pura é intrinsecamente cartesiana, a teoria neoaustriaca - sustenta-se aqui - é anticartesiana. Hayek, que se declara um racionalista evolucionáio seguidor de Mandeville. Hume e Menger, opõe-se explicitamente ao que ele mesmo denomina de racionalismo construtivista, originado na tradição de Bacon, Hobbes e Descartes, entre outros. Ele atribui particularmente a Descartes a origem da concepção, para ele detestável, segundo a qual "todas as instituições humanas úteis são ou devem ser criação deliberada da razão consciente" (Hayek, 1967, p 85) O construtivismo - raciocina - que se deriva diretamente do esprit géométrique, leva necessariamente a questionar a racionalidade das instituições herdadas do passado e que têm sido respeitadas, muitas vezes, inconscientemente Pois, é-lhe inerente só tolerar o que se origina da razão demonstrativa, ou seja, da capacidade de alcançar a verciade por meio do raciocínio dedutivo que parte de premissas óbvias e indubitáveis

Antes de prosseguir, mostrando como as concepçōes de Hayek se opũem, ponto por ponto, às teses aqui utilizadas para caracterizar o cartesianismo, é preciso ver de que forma o construtivismo se mostra na teoria neoclássica. Antes de tudo, manifesta-se por meio do reducionismo que manda centrar toda a explanação dos fatos sociais nas ações dos agentes individuais. Pois, para obedecê-lo, torna-se necessário ocultar, ao nível da teoria (ainda que não, evidentemente, ao nível das considerações circunjacentes), justamente as instituiçōes que constituem a chamada economia de mercado. ${ }^{12}$ Isto se expressa na afirmação segundo a qual, nesta teoria, "a economia fica completamente descrita pelas preferéncias e

\footnotetext{
11 Hahn rejeita, como alternativa à teoria pura, o historicismo, o qual supostamente descobre leis de desenvolvimento histórico, porque este seria um projeto de elaborar uma "história sem história" (history-free history) (Hahn, 1991b, p. 68). Isto que ele chama de historicismo, entretanto, deveria receber o nome de determinismo histórico.

${ }^{12}$ Esta tese se encontra demonstrada cabalmente num texto de De Villé (De Villé, 1990)
} 
dotaçóes dos agentes e pelos conjuntos de produção das firmas" (proposição "i", anteriormente mencionada). A presença de uma instituição inexplicada nesses termos já seria uma negação do próprio principio metodológico adotado e uma negação da razão cartesiana que está inscrita, como se viu, na própria caraterização do agente econômico da economia neoclássica.

O construtivismo manifesta-se também de outro modo na teoria neoclássica. Para apresentá-lo, é preciso ver primeiro que esta teoria se encontra na tradição de uma corrente do utilitarismo que, segundo Hayek, carateriza-se pela "demanda de que toda ação deve ser julgada com plena consciéncia de seus resultados previsiveis". O que, por um lado, anula o papel da herança normativa na sociedade - acentua - e, por outro, alimenta a visão moderna pela qual "o homem pode efetuar uma ordem social desejável, arranjando todas as suas partes e conhecendo completamente todos os fatos relevantes" (Hayek, 1967, p. 8). Visto isso, percebase, agora, como esta exigência se cumpre na resoluçāo do problema da estabilidade do equilibrio, por meio do tâtonnement walrasiano, o qual é baseado, como bem se sabe, na figura do leiloeiro. Note-se, para tanto, que este, ao invés de atuar ao modo de uma pessoa, ou mesmo como uma mão invisivel, ${ }^{13}$ na verdade, funciona como um autômato sinalizador que produz automaticamente preços, calcula excessos de demanda (e oferta) e transmite informações centralizadamente para todos os agentes econômicos. Assim, estes agentes tornam-se conhecedores de todos os fatos relevantes, podendo compatibilizar perfeitamente as suas preferências para realizar, em seqüência, as trocas. A ação econômica, deste modo, ajusta-se ao paradigma utilitarista referido e criticado por Hayek.

Para mostrar como as idéias neo-austriacas se opõem às do cartesianismo, é preciso começar pela ontologia. De fato, é necessário ver como Hayek, abrindo-se a uma concepção de evolução histórica, supera o dualismo cartesiano e resolve o seu problema inerente de interelacionar adequadamente o mundo do pensamento e o mundo natural. Estes dois reinos, é bom recordar aqui, apresentavam-se como infinitamente distantes na compreensão de ciência que se conforma ao legado de Descartes, já que são aí concebidos como esferas absolutamente diferentes e independentes entre si. Nesta tradição, avulta a dificuldade de conciliar o pensamento, que convive com a liberdade e a clarividência, com uma naturalidade, que é cega e determinada. Ela se mantém, nas palavras de Hayek, na concepção "da mente humana como uma entidade que existiria fora da ordem da natureza e da sociedade" (1985, p. XLIV)

Hayek, nesse ponto, segue as sugestōes de Popper no sentido de compreender a evolução do homem como desenvolvimento gradativo dos seus meios de controle

${ }^{13}$ Frank Hahn denomina a teoria walrasiana de teoria pura da mão invisivel, supondo que ela veio à luz, finalmente, para tornar rigorosas as idéias de Smith (Hahn, 1981, p 2). Apesar de sua autoridade no assunto, duvida-se aqui que o conceito neoclássico de tátonnement possa ser identificado com o conceito smithiano de mão invisível. Este último pressupõe um agente não apenas limitado na amplitude do conhecimento - ainda que muito mais limitado do que o agente neoclássico - mas, em especial, um agente racionalmente imperfeito que se engana sobre as suas próprias preferências e comete erros cognitivos. Por isso mesmo, a mão invisivel não se limita a exercer um papel meramente informativo tal como o leiloeiro, mas vem a ser uma fonte importantissima de racionalidade coletiva. Enquanto que o primeiro exerce apenas uma função sinalizadora, a mão invisivel tem funções motivadoras e mesmo criticas. 
do mundo natural. Rompendo com o inatismo cartesiano, Popper propõe que estes meios crescem no tempo. Rompendo, também, como o seu dualismo, propõe que eles crescem não só no mundo do pensamento mas também fora dele, ou seja, no mundo dos significados objetivos. A consciência, um desses meios, é vista então como resultado de um movimento progressivo que começou, há milênios atrás, como mera reação instintiva do cérebro às interferências externas e que acabou se transformando em capacidade de controle racional do ambiente. A consciência não ocupa, entretanto, o posto mais aito na hierarquia dos meios de controle. $\mathrm{Na}$ concepção evolucionária de Popper, ela está subordinada aos "sistemas lingüísticos exossomáticos ${ }^{\text {14 }}{ }^{14}$ que habitam o mundo das idéias objetivas, ou seja, as instituições normativas da sociedade, tais como as tradições teóricas, os sistemas legais e o complexo herdado das normas sociais.

Este outro mundo, que é produzido aos poucos e aos poucos vai sendo modificado pelo homem, de modo intencionado ou não, regula amplamente os estados de consciência do homem e o seu modo de atuação na natureza. Pensando a interação do mundo subjetivo, com o "universo dos significados" e com o mundo natural, Popper encontra uma solução não teológica para o "problema de Descartes" (Popper, 1975). Sob esta luz, Hayek pode criticar a dicotomia cartesiana entre o natural (aquilo que é indiferente ao designio humano) e o artificial (o que resulta de sua deliberaçãa). Esta oposição, segundo ele, "contribuiu enormemente para a negligência e para a má compreensão de algo crucial, ou seja, do prisŁesso exossomático de evolução cultural produtor das tradições que determinam o desenvo/vimento da civilização" (Hayek, 1988, p. 144). Esta consideração the permite negar que a eficácia eventual das açōes humanas possa ser atribuída sobretudo à competência deliberativa, para afirmar que para esta eficiência contribuem, de modo essencial, muites instituições da sociedade que foram criadas cegamente, sem qualquer propósito específico Aliás, é também este foco de iluminação que vai lhe permitir repensar as questões da ordem social e da racionalidade de um modo que se afasta daquele da teoria neoclássica.

Para fazer compreender a noção de ordem social, Hayek procura mostrar que ela é constituida por um substrato não redutivel ao natural, já que sua existência depende da ação do homem, e não redutivel ao artificial, já que não resulta de sua deliberação Este substrato, algo que resulta da ação do homem mas não de sua intenção, vem a ser, pois, "socionatural". Nãn se pode dizer, entretanto - è evidente - que a ordem social seja formada exclusivamente por este tipo de realidade. Pois, muito do que aí existe é produto consciente da ação humana. Hayek, ao invés de apresentar uma dialética da constituição do social que contempla a transformação do artificial em "socionatural", e vice-versa, prefere fornecer uma dicotomia entre o que ai deve ser visto como ordem construida, destinada a fins especificos, e ordem espontânea, estrutura evoluída gradativamente que possibilita a realização de múltiplos propósitos. Segundo ele, a ordem social é composta de elementos "socionaturais" e de elementos artificiais, mas estes elementos não podem ser combinados em quaisquer proporções. Os

14 Popper designa por exossomáticas todas as extensōes de si mesmos desenvolvidas pelos animais fora de seus corpos e necessárias à sua própria sobrevivência, tais como os ninhos, as teias, as picadas etc. 
primeiros, de que aliás os segundo dependem, por extrapolarem a capacidade humana de compreensão, não podem ser manipulados ao bel-prazer do homem apenas podem ser cultivados para que a riqueza brote e cresça.

A primeira caracteristica do cartesianismo anteriormente referida foi relacionada à concepção de economia da teoria neoclássica. Logo, faz-se necessário considerar aqui a concepção de economia que aparece na teoria neo-austríaca. ${ }^{15}$ Para Hayek, a ordem social que denomina (recordando Smith) de grande sociedade está centrada na economia, a qual vem a ser sobretudo um conjunto de instituições, em parte espontâneas em parte legalmente construídas, que permitem a divisão do trabalho - e, assim, um número incontável de relações sociais mediadas - em escala mundial. Logo, nesta perspectiva, a economia não pode ser descrita exclusivamente pelas dotações e pelas preferèncias tecnológicas e utilitaristas dos agentes, ainda que estes elementos também apareçam no seu quadro. A economia é vista como uma ordem espontânea que possibilita a interação de indivíduos $e$ organizações entre si e com a natureza, segundo o seu auto-interesse, conforme certas regras abstratas e sem se submeter a qualquer plano global. Ao invés de pensar o mercado como uma máquina, a economia neo-austríaca concebe-o como processo de mercado.

A segunda característica relacionada faz referência à concepção de razao. Se a razão cartesiana é "egocentrada", dedutivista e engenhosa, a razão evolucionária é "sociocentrada", interpretativa e adaptativa. Tais pontos transparecem em afirmações do próprio Hayek O primeiro deles mostra-se assim: "o cartesianismo... assume [que] a civilização é produto da razão .. mas se deve enxergar a razão como produto da civilização" (Hayek, 1967, p 86). O segundo manifesta-se numa referência abonadora do pensamento medieval: então, afirma, "a razão significava principalmente a capacidade de reconhecer a verdade, assim que ela é encontrada, ao invés da capacidade de raciocínio dedutivo a partir de premissas explícitas" (idem, p. 84). O terceiro apresenta-se na sua aprovação à tese que absolve a razão da faculdade de julgamento moral: "a razão não é juiz" - sustenta - " "mas um instrumento" (idem, p. 87), um meio de adaptação ao entorno social e natura! ${ }^{16} \mathrm{~A}$ razão construtivista, para Hayek, abusa da razão nos planos cognitivo e prático. ${ }^{17}$

No plano da teoria, este conceito de razão marifesta-se na compreensão neoaustriaca do agente econômico que participa do processo de mercado. De partida,

\footnotetext{
15 É sabido que Hayek emprega o termo "cataláctica", ao invés de "economia", para se referir ao sistema econômico capitalista, pois considera que "economia". designa uma ordem feita e não uma ordem espontânea.

16 "As regras da moralidade nåo são resultados da nossa razåo" - reforça Hayek, citando Hume, para completar: "nossos valores... săo os fins que a razåo serve e que ela nåo determina" (Hayek. 1967, p. 87).

${ }^{17}$ A critica de Hayek ao cartesianismo não pode ir muito longe, ainda que ele esteja meio certo - e meio errado, também - quando diz que a razăo é produto do desenvolvimento humano É quase trivial dizer que tal racionalismo é um resultado histórico da época moderna, expressão do homem que se julga emancipado das tradições medievais. Por outro lado, também é trivial perceber que sem o amplo domínio do espírito construtivista que vem movendo a ciência e a geração de tecnologias há vários séculos, as instituiç̧̃es do capitalismo seriam um invólucro vazio. O que em outro texto foi dito continua, pois, certo: "à medida que atribui a adoçăo dessa atitude em teoria a 'mentalidade típica do engenheiro', fica claro que objeta ao extravasamento da racionalidade dominante na esfera económica ao interior da teoria [€ da política ] económica" (Prado, 1991, p. 9n).
} 
deve-se ver que, para Hayek, é absurdo começar a análise do mercado supondo que todos os fatos são conhecidos de todos, pois assim se supõe resolvido o problema que o mercado, descentralizadamente, resolve. Segundo ele, a competição é, sobretudo, um processo de descoberta: "a competição é valiosa porque e à medida que os seus resultados são imprevisiveis" (Hayek, 1978, p. 180). Não só não se pode prever o comportamento dos agentes como também não se pode adivinhar o resultado do processo como um todo - este caminha de um modo transcendente à capacidade humana de conhecer. Imersos na ordem espontânea, os agentes são entendidos como seres adaptativos, severamente limitados na capacidade de conhecer, que tem constantemente de interpretar os sinais do mercado, descobrir o que desejam e fazer uso de fatos particulares para alcançálos. Nessa atividade, cada um deles é guiado pela mão invisivel: "os preços dirigem sua atenção para o que importa descobrir sobre o que o mercado tem a oferecer em termos de bens e serviços" (idem, p. 182). Na leitura neo-austriaca, é o sistema de preços - um modo de auto-organização exossomático que se expressa na linguagem do dinheiro - , que torna possivel a atividade racional dos agentes econômicos. Pois a racionalidade humana é fraca; é pouco o que eles conhecem e muito o que têm de pressupor que sabem.

A competição é inerente, pois, até certo ponto, há frustração das expectativas e das intenções. Isto implica que à visão neo-austriaca é estranha a idéia da perfeição do sujeito - terceira caracteristica do cartesianismo antes referida. Ao contrário, o agente ai concebido, inerentemente, não sabe tudo o que precisa saber para tomar boas decisões: o conhecimento necessário, diz Hay@k, nunca existe de forma concentrada, mas somente na forma de "porçס̃es dispersas de conhecimento incompleto, freqüentemente contraditório, mantidas pelos individuos" (Hayek, 1948, p. 77). À perspectiva neo-austriaca também é estranho o objetivismo. Em Economia e conhecimento, um de seus textos mais conhecidos, Hayek combate o emprego equivocado do termo "dados" na teoria econômica. $\dot{E}$ certo, o agente age - convém - com base em "dados", mas estes não são fatos objetivos, mas sim fatos detidos subjetivamente, ou seja, "fatos que estão presentes na mente da pessoa agente" (Hayek, 1948, p. 39). Toda teoria econômica tem de trabalhar, também é certo, com "o conceito de pessoa isolada que age... de acordo com um plario pré-concebido... mas cste pode estar baseado, evidentemente, em supostos errôneos sobre os fatos externos" (Hayek, 1948, p. 37).

Hayek, evidentemente, não correlaciona a verdade à capacidade de julgamento, ou seja, à razão como tal e, nesse sentido, é um anti-racionalista - termo, aliás, que ele não recusa (Hayek, 1967, p. 84). Isto se pode concluir de muito do que foi aqui mencionado. Contudo, vale mostrar que esta posição aflora diretamente do sentido associado ao termo "presunção fatal", ${ }^{18}$ criado por ele para minar todo pensamento socialista: "isto eu chamo de presunção fatal: a idéia de que a aptidão para adquirir conhecimento advém da razão" (Hayek, 1988, p. 21).

A quinta característica do cartesianismo - uma confiança acentuada no método axiomático e dedutivo - encontra também oposição no pensamento neo-austríaco. Não se observa, entretanto, no pensamento hayekiano uma condenação frontal da

${ }^{18}$ Hayek emprega em inglês o termo "fatal conceit" que poderia ser melhor traduzido, se não fosse tão empolado, por "conceito presunçoso fatal". 
teoria do equilibrio geral. As objeçōes se mostram de inicio como mera divergência quanto à interpretação dos resultados obtidos pelo "tratamento tradicional da análise de equilíbrio". Em Economia e conhecimento, Hayek inicia toda uma critica à "lógica pura da escolha", partindo da idéia de que as suas tautologias - o emprego do termo é dele - permanecem vazias de significado empírico até que se diga como o conhecimento é adquirido, conservado e transmitido (Hayek, 1954). O que de início parece pouco, entretanto, logo se revela bem substantivo. Tão cedo se percebe que assim a teorização econômica centrada na idéia de equilíbrio é substituída por uma abordagem processual centrada na questão da coordenação das ações, pode-se avaliar melhor a distância que separa as duas linhas teóricas revistas. A economia deixa de ser entendida como máquina e passa a ser compreendida como processo auto-organizado, ou seja, como ordem espontânea. Quais as implicações metodológicas desta ruptura com o cartesianismo no plano da ontologia econômica?

Em The fatal concept, obra tardia deste autor, Hayek critica diretamente o justificacionismo, ou seja, o principio metodológico de que só se pode manter como conhecimento o que está muito bem fundamentado. Em particular, ele objeta ao justificacionismo racionalista que procura fundaçōes firmes para o saber, por meio do trabalho solitário da razão que busca começos claros e certos. Tal princípio que se infiltrou amplamente na visão moderna de ciência, por mais firme que pareça argumenta - não pode ser sustentado ele opõe razão à tradição, mas o pensamento nunca é autônomo: "é obviamente impossivel não obedecer a uma tradição" (Hayek, 1988, p. 61). Ora, tal justificacionismo fornece um suporte importante à reivindicação de universalidade do método axiomático e dedutivo. Eis, porém, que ao colocar as coisas desse modo, Hayek já põe a mostra que essa pretensão é falsa. A razão não é todo-poderosa; nem tudo o que existe the pode ser subordinado.

Segundo Hayek, a ordem espontânea do mercado, em virtude da sua própria natureza, não pode ser explicada dedutivamente a partir de axiomas verdadeiros e certos. Não é isto, entretanto, o que pensa o construtivismo Se esta última perspectiva está correta, será preciso conceder, então, que "muitas instituições. do capitalismo, as quais não vêm de encontro a este requerimento ou critério, são... 'não razoáveis' ou 'não cientificas' " (Hayek, 1988, n. 66). Uma tal afirmação, porém, seria ingênua Ao sugeri-la, o renovador da economia austriaca yuer mostrar apenas, desafiadoramente, que o produto histórico das tradições, ou seja, do que foi feito cegamente num processo evolutivo, não pode ser justificado ou deduzido de principios bem justificados. Assim como as regras que mantêm a economia de mercado, "os principios morais tradicionais etc." - exemplifica - não são justificáveis racionalmente" (idem, p. 68). Isto não significa, porém, que a ordem expontânea não possa ser compreendida. Ao contrário, Hayek julga que é possivel apreendê-la por meịo da "reconstrução racional", um procedimento teórico que não quer deduzir resultados particulares de axiomas e supostos gerais, mas que pretende tão somente fornecer uma "história conjectural" - ou seja, uma história de "como o sistema pode ter vindo a existir" (idem, p. 69). Assim, se pode descobrir como subsiste, para melhor poder conservá-lo ou mesmo melhorá-lo.

Logo, na perspectiva do pensamento neo-austriaco, o tribunal de última instância do conhecimento não pode ser a razão, tal como veio estabelecer a sexta carateristica do cartesianismo, antes mencionada. Contra a época moderna, ele 
sustenta não só que a tradição é uma autoridade legitima, mas que ela é a única autoridade que não se pode deixar de obedecer, de algum modo. Mais do que isso, quase chega a dizer que a tradição é quem pensa na mente do homem histórico: "em todo nosso pensamento, somos guiados (senão mesmo operados) por regras de que não estamos conscientes" (Hayek, 1967, p. 87). Assim, as tradições se mostram como verdadeiros sujeitos históricos. O velho Hayek é, pois, um tradicionalista que admite, apenas, um reformismo limitado.

Finalmente, resta discutir a sétima característica do cartesianismo, a saber, aquela que confere um caráter exclusivamente epistemológico à experiência Nesta perspectiva - note-se - o conhecimento é entendido como algo que acontece na relação do sujeito com o objeto, no contato entre estas duas esferas exteriores entre si. O mundo interior do pensamento e o mundo exterior da natureza entram em conexão - acredita o cartesianismo - por meio dos sentidos. Em consequência, estes são apresentados como fonte primária da experiência. As sensações transformadas em idéias e noções traduzem a experiência. A linguagem é vista apenas em sua dimensão cognitiva.

Para Hayek, contrariamente, a experiência tem um caráter ontológico, ou seja, ela é compreendida como formadora do ser e do mundo do homem. Eis que isto se pode descobrir em seus textos sem grande dificuldade. $O$ transcrito em seqüência $\dot{\epsilon}$ bem significativo:

- ... a capacidade do homem de pensar não é uma dotação natural do individuo, mas uma herança cultural, algo que é transmitido... de modo implicito, principalmente por meio do aprendizado da linguagem. A extensão com que a linguagem apreendida na infância determina toda nossa maneira de pensar, visão e modo de interpretação do mundo é, provavelmente, muito maior do que estamos conscientes. Näo é somente que o conhecimento das gerações prévias seja transmitido por meio da linguagem; a própria estrutura da linguagem implica certos modos de ver a natureza do mundo... dentro dos quais movemo-nos sem ter consciência disto... Este fenômeno do aprendizado implícito é claramente um dos elementos mais importantes da transmissão cultural, a qual até agora entendemos só imperfeitamente" (Hayek, 1967, p. 86, 87).

É importante notar agora como essa compreensão do mundo se relaciona com a idéia de equilibrio. Se na perspectiva da ontologia cartesiana, o equilibrio é o estado de repouso possivel da máquina econômica, da perspectiva da ontologia hayekiana ele é a meta objetiva que o processo de mercado incessantemente busca, anonimamente, sem nunca alcançar este objetivo, plenamente. Este é um ponto importante que requer melhor elaboração.

$\dot{E}$ preciso ver que, para Hayek, o equilibrio è um estado ficticio em que a economia ni nca pode se encontrar, ainda que seja um estado possivel. Para compreender isto é necessário verificar como vem a ser definido: equilibrio, segundo este pensador, é aquele estado concebivel em que as previsões de todos os agentes econômicos sobre todos os eventos externos relevantes, inclusive os planos dos outros agentes, mostram-se corretas. Dada a complexidade da economia e a falibilidade do conhecimento, a probabilidade de tal ocorrência afigura-se como praticamente nula. Mas isto não é tudo. Pois, para ele, a consideração de que há "sistemático desapontamento das expectativas é de crucial importância para o entendimento do funcionamento da ordem mercantil" (Hayek, 1978 , p. 185). Pois, são as correções dos erros de predição balizadas pelo 
funcionamento do sistema de preços que movem a economia para o equilibrio.

Hayek considera, pois, necessário adotá-lo em teoria, já que para ele o processo económico não se apresenta como caótico ou desordenado. Ao contrário, pensando em seu comportamento real, vê existir uma tendência equilibradora operando na economia. Este autor, entretanto, é extremamente crítico do modo pelo qual tal conceito é empregado na Economia Pura. Pois, "tal equilibrio pressupõe que os fatos [relevantes] já foram descobertos e que a competição já cessou" (idem, $\mathrm{p}$ 184). Ou seja, tal teorização assume como acabado o processo de descoberta de informações em que a competição propriamente consiste. Assim, considera-se como quase resolvido o problema complexo de coordenação que o processo anônimo de competição soluciona bem e que nenhuma capacidade humana de calcular pode resolver. Por isso, prefere concebê-lo como uma meta ideal da qual o processo de mercado incessantemente se aproxima, configurando nesta busca uma ordem com elevado grau de aproximação Nesta perspectiva, não vale a objeção de Joan Robinson, pois "a passagem do tempo é essencial para dar ao conceito de equilibrio algum significado" (Hayek, 1948, p 37)

Se assim é, eis que o agente que habita tal "sistema auto-organizador" não pode ser concebido como passivo. Para se adaptar às condições permanentemente cambiantes, ele precisa procurar a informação emergente no mercado, interpretando-a convenientemente, pois "a orientação principal que os preços oferecem não é tanto sobre como agir, mas sobre o que faze:"-(Hayek, 1978, p. 187). O agente deve, pois, responder sempre à frustração de suas expectativas. Ele tem de descobrir as boas oportunidades oferecidas pelo mercado, assim como fugir das circunstâncias que se the afiguram desvantajosas. ${ }^{19}$ Os próprios fins que persegue não estão de antemão determinados A ordem espontânea, segundo Hayek, permite que um conjunto infinito de fins particulares sejam buscados $E$ possibilita que novos fins sejam criados. A autonomia do agente, entretanto, é limitada, já que as suas ações são guiadas pela mão invisivel e os resultados que delas decorrem são dependentes de um processo cego que não controla e que se afigura como uma loteria. ${ }^{20}$

É preciso deixar agora que o próprio Hayek ilustre com precisão o que vem a ser esta heteronomia:

O mais importante, porém, é a relação de uma ordem espontânea com o conceito de propósito. Uma vez que essa ordem não foi criada por um agente externo, ela tampuuco pode ser propositada.. Mas, num outro sentıdo, também se pode dizer que a ordem repousa em ação 'propositada' de seus elementos, 'propósito' significando, neste caso, é claro, apenas que as ações dos elementos tendem a assegurar a preservação ou a restauração dessa ordem. O uso do termo 'propositado', neste sentido, como uma espécie de 'taquigrafia teleológica' ... não é contestável. entendamos simplesmente que [os

\footnotetext{
${ }^{19}$ Um sociólogo funcionalista americado, J. Alexander, apresenta um conceito de ação que ajuda a compreender Hayek. Ele concebe "a açăo como movimento em duas direçסes: interpretaçăo e cálculo estratégico. A açăo é compreensão; é também, simultaneamente, prática e cálcuio utilitário" (Alexander, 1988, p. 312).

20 A açăo humana no interior do sistema económico, tal como vista por Hayek, pressupõe a existência de uma certa liberdade. Por mesmo dizer, com Ege, que "a liberdade da açăo dos individuos constitue a condiçăo fundamental da catalaxia" (Ege, 1992, 1013). Esta liberdade, entretanto, é negativa já que diz respeito ao direito efetivo de não obedecer regras específicas sobre o que fazer e como fazer, assim como de não se sujeitar à vontade arbitrária de outrém.
} 
elementos da ordem] adquiriram regularidades de conduta propicias à manutenção da ordem... Em geral, porém, é preferivel evitar neste contexto o termo 'propósito' e falar, em vez disso, de 'função" (Hayek, 1985, p. 41).

Hayek critica o racionalismo construtivista, para pôr em seu lugar um racionalismo evolucionário, que é, de fato, anti-racionalista. Ele rejeita a ontologia mecânica do cartesianismo, para pôr em seu lugar uma ontologia social funcionalista. Em sua teoria, o agente econômico não é, parece certo, o nulo que se apresenta na teoria de equilibrio geral, mas está reduzido à condição de função.

\section{BIBLIOGRAFIA}

ALEXANDER, J. C., Action and its environments. In: Action and its environments - toward a new synthesis. New York: Columbia University Press, 1988, p. 301-333.

ADDLESON, M., "Radical subjectivism" and the language of austrian economics. In: Subjectivism, intelligibility and economic understanding. Ed.: KIRZNER, I. New York: New York University Press, 1986.

BERNSTEIN, R. J., Beyond objectivism and relativism - science, hermeneutics, and praxis. Philadelphia: University of Pennsylvania Press, 1988.

BURTT, E. A., As bases metaffsicas da ciencia moderna. Brasilia: Editora UNB, 1991

DESCARTES, R., Discurso do Método. in: Descartes. Os Pensadores. Såo Paulo: Abril Cultural, 1983a, p. 25-71.

Meditaçס̋es. In: Descartes. Op. cit., p. 73-142.

$\overline{\mathrm{DE}}$ VILLE, $\mathrm{Ph}$., Comportements concurrentiels et équilibre général: de la nécessité des institutions. In: Economie Appliquee, volume 43, $\mathrm{n}^{\circ} 3,1990$, p. 9-34.

EGE, R. Émergence du marché concurrentiel et évolutionnisme chez Hayek. In: Revue Économique, vol. 43 (6), novembro de 1992, p. $1007-1036$.

FEIJO, R. A contribuiç̧o de F. A. Hayek para o estudo do mercado: uma contribuiçăo metodológica. Dissertaçăo de mestrado em andamento, 1994.

HAHN, F., On the notion of equilibrium in economics. Cambridge: Cambridge University Press, 1973. - Reflections on the invisible hand. Warwick Economic Research Papers, 1981.

- The neo-ricardians in: Cambridge Joumal of Economics, volume 6, 1982, p. 353-374

in praise of economic theory. Londres: University College London, 1984.

The next hundred years. In: Economic Joumal, vol. 101, janeiro de 1991a, p. 47.50.

History and economic thecry. In: Issues in contemporary economics. Ed K J Arrow, vol. 1. Londres: Macmillan, 1991b, p. 67-74.

HAYEK, F. A., Economics and knowledge. In: Individualism and economic order South Bend: Gateway, 1948, p. 33-56.

The use of knowledge in society. In: Individualism.. Op. cit., p. 77.91.

Kinds of rationalism. In: Studies in Phwosophy, Politics and Economics inicago: The University of Chicago Press, ^967, p. 82-95.

Competition as discovery procedure. In: New studies in Philosophy, Politics, Economics and

the history of ideas. Londres: Routledge \& Kegan Paul, 1978, p. 179-190.

Direito, legislaçăo e liberdade - normas e ordens. São Paulo: Visão, 1985.

The fatal conceit - the errors of socialism. Chicago: Universily of Chicago Press, 1988.

KOPPL, R., Price theory as physics: the cartesian influence on Walras. In: Methodous, vol. 4, $n^{\circ} 2$, dezembro de 1992, p 17-28.

MIROWSKI, P., The philosophical basis of institutionalist economics. In: Journal of Economic /ssues, vol. 21, $n^{\circ} 3$, setembro de 1987, p. 1001-1038.

POPPER, K., De nuvens e relógios. In: Conhecimento objetivo - uma abordagem evolucionária. São Paulo: USP/ltatiaia, 1975, p. 193-233.

PRADO, E. F. S., Economia como Ciencia. São Paulo: IPE/USP, 1991. 48.

Metodologia da Economia: individualismo versus holismo? In: Impulso, vol. 13, 1994, p. 29-

A constelação pós-walrasiana. In: Revista de Economia Politica, a ser publicado em 1994.

ROBINSON, J., History versus equilibrium. In: Contribuitions to modem economics. Oxford: Basil 
Blackwell, 1978, p. 126-136.

SOROMENHO, J. E. C., Um estudo sobre as origens da critica de Hayek ao conceito de equillbrio.

Tese de doutoramento. Såo Paulo: IPE/USP, 1994.

WALRAS, L., Compendio dos elementos de economia politica pura. Såo Paulo: Abril Cultural, 1983.

\section{ABSTRACT \\ THE NEOCLASSICAL THEORY AND THE \\ NEO-AUSTRIAN THEORY RELATED TO THE CARTESIAN LEGACY}

This paper was writen under the supposition that to pay attentions to the philosophical foudations of economic theories are important either to understand them and to know its weakness and limits. Under this view, it is compared neoclassical and neo-austrian theory investigating if they accept or reject the Cartesian legacy. To characterize the pure neoclassical theory it is examined Frank Hahn's papers. To characterize the neo-austrian theory it is analyzed Friedrich Hayeck's papers. An important idea of the paper consists in showing the differences between the equilibrium concepts and adopted by these authors. 